\title{
Adult polycystic kidney disease: knowledge, experience, and attitudes to prenatal diagnosis
}

\author{
Kathy A Hodgkinson, Lauren Kerzin-Storrar, E Ann Watters, Rodney Harris
}

\begin{abstract}
One hundred and ninety subjects from 100 adult polycystic kidney disease (APKD) families on the North Western Regional Genetic Register were interviewed to determine the likely demand for prenatal diagnosis. A detailed questionnaire was used to assess understanding and experience of clinical, therapeutic, and genetic aspects of APKD. Major features of the disease (presence of renal cysts which can lead to renal failure) and forms of therapy (dialysis and transplantation) were known; knowledge of less common features was related to experience. The cohort had had genetic counselling and the majority knew the risk to their own offspring, although the mechanics of the mode of inheritance was often misunderstood. Uptake of presymptomatic ultrasound testing was high, and some implications of early diagnosis are noted. A minority changed their reproductive behaviour as a result of APKD, and although the majority felt a prenatal test should be available, only $23 \%$ at high risk of passing on the disease and contemplating children felt they would be interested, and so far only one request for prenatal diagnosis has been received. Thus, demand appears to be low and to be related to perception of the seriousness of APKD.
\end{abstract}

Adult polycystic kidney disease (APKD) was first described in $1888^{1}$ and falls into type 3 of Osthanondh and Potter's classification of cystic kidney disease. ${ }^{2}$ Its hereditary nature was noted as early as $1899,{ }^{3}$ although Cairns ${ }^{4}$ first documented its autosomal dominant mode of inheritance. Approximately 1 in 1000 newborns carries the gene. It has been suggested that the penetrance is $100 \%$, that is, all gene carriers

Regional Genetic Service, St Mary's Hospital, Hathersage Road, Manchester M13 0JH.

K A Hodgkinson, L Kerzin-Storrar, E A Watters, R Harris Correspondence to Mrs Kerzin-Storrar.

Received for publication 29 August 1989.

Revised version accepted for publication 16 March 1990. develop symptoms if they live long enough, and that the mutation rate is high $\left(6.5\right.$ to $\left.10 \times 10^{-5}\right) .^{5}$

The condition is extremely variable. Some subjects maintain normal renal function into their $80 \mathrm{~s}$, others are affected neonatally, ${ }^{6}$ while the majority experience renal insufficiency by middle life. Whether neonatal APKD is aetiologically distinct from adult onset APKD has yet to be determined. ${ }^{7}$

APKD is characterised by bilateral renal cysts, usually leading to renal insufficiency by the fifth to sixth decades of life. The commonest manifestations are pain, hypertension, urinary tract infections, and haematuria with palpable kidneys. ${ }^{89}$ APKD patients account for about $10 \%$ of all those on dialysis, ${ }^{10}$ and it has been estimated that $2 \%$ of affected subjects will develop end stage renal failure by the age of $40,23 \%$ by the age of 50 , and $48 \%$ by the age of $70 .{ }^{11}$ Transplantation is a valid treatment for APKD patients in renal failure. Liver cysts are present in about $30 \%$ of patients, and cysts may also occur in the pancreas, spleen, lung, and ovary. ${ }^{12}$ The liver cysts have been considered to be benign, but there is evidence that they can cause severe problems. ${ }^{13}$ Cardiovascular abnormalities have been noted, ${ }^{14}$ and the association of intracranial aneurysms leading to cerebral haemorrhage is well documented. ${ }^{15} 16$

Children of affected persons have a $50 \%$ risk of carrying the gene, and young people making reproductive decisions are often concerned to know their carrier status. Intravenous urography, nephrotomography, radionuclide scanning, arteriography, and computed tomography have all been previously used to assess carrier status. The current preferred method is ultrasonography. ${ }^{17-19}$ It is painless and noninvasive, but its accuracy at an age when most people are making reproductive decisions has been questioned. $^{20}$

Although ultrasound screening of potential gene carriers is well established, prenatal diagnosis is not. Cysts may occasionally be detected prenatally by ultrasonography, but then only in the third trimester of pregnancy. ${ }^{21} 22$

A major advance in the study of APKD was made by the discovery of a gene probe closely linked to the disease locus on the short arm of chromosome $16^{23}$ Results obtained using the 3'HVR probe of Reeders have a $5 \%$ error rate because of recombination. A 
second bridging marker (24-1) has now been described, ${ }^{2+}$ which, used together with the 3 'HVR marker, gives an error rate of less than $1 \%$. The possibility of genetic heterogeneity has been raised, ${ }^{25} 26$ but so far has not been resolved. ${ }^{27} 28$

Application of these DNA markers permits both carrier detection and prenatal diagnosis in families with suitable pedigree structures; the first prenatal diagnosis for APKD using linked probes was carried out in $1986 .{ }^{29}$ Now that prenatal diagnosis is possible, the question arises of whether it will be an acceptable option to couples, given the late onset and partially treatable nature of the condition. In the study of Macinol et $a l^{30}$ only $7 \%$ of those surveyed would consider termination of an affected pregnancy, but both Macinol et $a l^{30}$ and Sahney et al ${ }^{31}$ found that people had little knowledge of the genetic and clinical aspects on which to base their decisions. In Manchester, a register of APKD families was established in 1980, based at the Regional Genetic Centre. We carried out a questionnaire survey to assess attitudes, knowledge of the condition, and the likely demand for prenatal tests among subjects on the register. We present here the results from 190 persons interviewed between January 1987 and June 1988.

\section{Methods}

In 1980 a voluntary and confidential register of genetic diseases was set up in the North Western Regional Genetic Centre based at St Mary's Hospital, Manchester. The purposes of the register are several, including genetic counselling for affected subjects, assessing and explaining risks to family members, annual recall for relatives at high risk, and presymptomatic ultrasound testing at the appropriate age. Annual recall and medical review in the department is continued for those shown to be affected after testing, with the aim of preventing complications. At present there are 129 registered APKD kindreds, out of which 431 persons, either affected or at high risk, are recalled annually.

APKD has a reported gene frequency of 1 in $1000 . .^{5}$ The population of the North Western region is just over 4 million; we would therefore expect about 4000 gene carriers, although at the moment we have only 420 affected subjects registered. Ascertainment, even allowing for late expression, is incomplete because the APKD register has concentrated on providing a joint clinical service with the renal unit at Manchester Royal Infirmary, rather than attempting to ascertain systematically every case in the region.

For this study we contacted all those aged between 18 and 45 on the register who had been previously counselled. These made up four groups of subjects according to status: (1) affected, (2) high genetic risk (at $50 \%$ risk), (3) low genetic risk (one or more negative presymptomatic tests by a consultant radio- logist), and (4) spouses of any of the above. Those agreeing to participate were then interviewed in their own homes by a genetic fieldworker (KAH). Interviews were carried out using a detailed questionnaire and responses were recorded by the interviewer. In addition to direct questions, opportunity for open ended discussion was given.

The questionnaire was divided into six sections: (1) background information, (2) knowledge and understanding of clinical aspects and available therapy, (3) knowledge of the mode of inheritance, (4) information regarding affected relatives, (5) presymptomatic, and (6) prenatal testing.

For sections (2) and (3) a person's overall knowledge was scored using lists of weighted facts which were considered necessary for the understanding of the condition (table $1 \mathrm{a}, \mathrm{b}, \mathrm{c}$ ). Based on these scores, knowledge was classified as excellent, good, fair, poor, and absent.

As many of the subjects had not been made aware of the possibility of prenatal diagnosis, an explanation was given regarding how a prenatal test works, including discussion of the gene markers and of chorionic villus sampling. In order to facilitate this, we used linkage and recombination diagrams, designed for any autosomal dominant condition.

\section{Results}

Of the 352 subjects contacted, 190 participated (table 2). The take up rate was $54 \%$ for the group as a whole, but only $19 \%$ participated from the high risk group. Of the 190 interviewed, $43(23 \%)$ were under the age of $25,87(46 \%)$ were aged between 25 and 35 , and 60 (31\%) were aged 36 and over. There were 114 females $(60 \%)$ and 76 males (40\%) (table 3 ).

Table la Clinical features.

\begin{tabular}{lcc}
\hline & $\begin{array}{c}\text { If mentioned } \\
\text { score }\end{array}$ & $\begin{array}{c}\text { Number (\%) of } \\
\text { subjects who } \\
\text { mentioned each } \\
\text { feature }\end{array}$ \\
\hline $\begin{array}{l}\text { Direct questions } \\
\text { Multiple renal cysts }\end{array}$ & 3 & $163(86)$ \\
Renal failure & 3 & $168(88)$ \\
Indirect questions & 2 & $85(45)$ \\
Pain & 2 & $50(26)$ \\
UTIs & 2 & $62(33)$ \\
Haematuria & 2 & $97(51)$ \\
Hypertension & 1 & $91(11)$ \\
Cysts elsewhere & 1 & $90(16)$ \\
Subarachnoid haemorrhage & 1 & $19(10)$ \\
Variable disease & 1 & \\
Usual late onset & 1 & \\
Other & & 1
\end{tabular}

Overall knowledge scores were tabulated by adding the scores for each feature mentioned and then put into the following categories: $0=$ absent, $1-5=$ poor, $6-12=$ fair, $13-17=$ good, $18+=$ excellent. 
Table Ib Therapy.

\begin{tabular}{lcc}
\hline & $\begin{array}{c}\text { If mentioned } \\
\text { score }\end{array}$ & $\begin{array}{c}\text { Number }(\%) \text { of } \\
\text { subjects who } \\
\text { mentioned each } \\
\text { form of therapy }\end{array}$ \\
\hline $\begin{array}{l}\text { Direct questions } \\
\text { Transplantation }\end{array}$ & 3 & $157(83)$ \\
Haemodialysis & 3 & $155(82)$ \\
$\begin{array}{l}\text { Indirect questions } \\
\text { Medical }\end{array}$ & 2 & $89(47)$ \\
$\begin{array}{l}\text { CAPD } \\
\text { Dietary }\end{array}$ & 1 & $33(17)$ \\
Monitoring & 1 & $53(28)$ \\
Other & 1 & $17(9)$ \\
\hline
\end{tabular}

Overall knowledge scores were tabulated by adding the scores for each form of therapy mentioned and then put into the following categories: $0=$ absent,$\quad 1-3=$ poor, $4-6=$ fair, $7-9=$ good, $10+=$ excellent.

Table Ic Genetics.

\begin{tabular}{lcc}
\hline & \multicolumn{1}{c}{ If mentioned } & $\begin{array}{c}\text { Number (\%) of } \\
\text { subjects who } \\
\text { mentioned each } \\
\text { feature }\end{array}$ \\
\hline $\begin{array}{l}\text { Direct questions } \\
\text { 50\% risk }\end{array}$ & 3 & $96(50)$ \\
Doesn't skip generations & 3 & $76(40)$ \\
Risk to offspring correct & 3 & $138(73)$ \\
Affects both sexes & 2 & $94(49)$ \\
Indirect questions & 2 & $82(43)$ \\
Caused by gene & 1 & $6(3)$ \\
Autosomal dominant & 1 & $14(7)$ \\
Other & & \\
\hline
\end{tabular}

Overall knowledge scores were tabulated by adding the scores for each feature mentioned and then put into the following categories: $0=$ absent , $1-2=$ poor, $3-8=$ fair, $9-11=$ good , $12+=$ excellent .

Table 2 Study cohort.

\begin{tabular}{|c|c|c|c|c|c|}
\hline & Affected & $\begin{array}{l}\text { High } \\
\text { risk }\end{array}$ & $\begin{array}{l}\text { Low } \\
\text { risk }\end{array}$ & Spouses & Total \\
\hline \multirow{2}{*}{$\begin{array}{l}\text { Invited } \\
\text { No reply/ } \\
\text { refused } \\
\text { Interviewed }\end{array}$} & 131 & 77 & 52 & 92 & 352 \\
\hline & $\begin{array}{c}46 \\
85 \\
(65 \%)\end{array}$ & $\begin{array}{c}62 \\
15 \\
(19 \%)\end{array}$ & $\begin{array}{c}20 \\
30 \\
(58 \%)\end{array}$ & $\begin{array}{c}34 \\
58 \\
(63 \%)\end{array}$ & $\begin{array}{c}162 \\
190 \\
(54 \%)\end{array}$ \\
\hline
\end{tabular}

Table 3 Sex of cohort.

\begin{tabular}{lrr}
\hline & \multicolumn{2}{c}{ Sex } \\
\cline { 2 - 3 } Status group & M & \multicolumn{1}{c}{ F } \\
\hline Affected & 26 & 59 \\
At high risk & 5 & 10 \\
At low risk & 15 & 17 \\
Spouses & 30 & 28 \\
Total & 76 & 114 \\
\hline
\end{tabular}

\section{KNOWLEDGE OF CLINICAL ASPECTS}

In response to direct questions, $174(92 \%)$ persons correctly named the condition, $163(86 \%)$ knew that the kidney contained bilateral cysts, and $168(88 \%)$ understood that there was a possibility of renal failure (table 1a). Asked to describe additional features of the

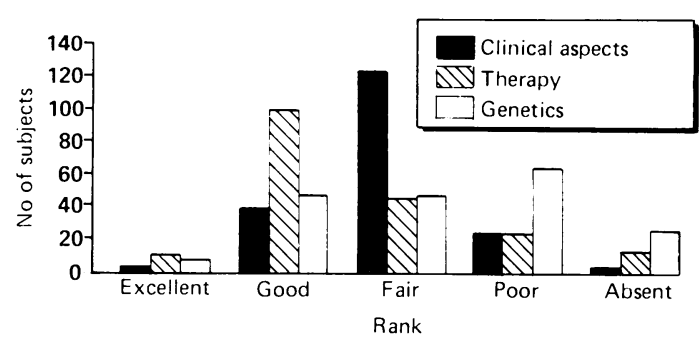

Histogram showing the ranked knowledge of clinical aspects, therapy, and genetics for the whole cohort.

disease, far fewer persons knew of the increased risk of high blood pressure, urinary tract infections (UTI), and haematuria, and these were those who had had experience of these, either personally or within the family. Only nine (5\%) mentioned the increased possibility of subarachnoid haemorrhages $(\mathrm{SAH})$, one of the more severe complications of APKD. Each of these was from a family in which SAHs had occurred. Forty-two $(22 \%)$ had a clinical knowledge score considered good or excellent, while $26(14 \%)$ had poor or absent knowledge (figure). None of the 15 high risk subjects had good or excellent knowledge and five $(33 \%)$ had poor or absent knowledge.

\section{KNOWLEDGE OF THERAPY}

In response to direct questions, $157(83 \%)$ subjects knew of the availability of transplantation, and 155 $(82 \%)$ of the possibility of dialysis (table $1 \mathrm{~b}$ ). When asked what other treatment was available, $53(28 \%)$ knew that dietary measures could be used and 89 $(47 \%)$ that medical intervention could help with symptoms. Looking at the personal experience of the affected subjects $(n=85), 60 \%$ have required little treatment other than monitoring at present, $30 \%$ are on dietary control, and $10 \%$ are on dialysis or have received a transplant. Of the whole cohort, $88(46 \%)$ have had relatives who have a transplant or are on dialysis. A total of $109(57 \%)$ had a therapy knowledge score considered good or excellent, while 36 (19\%) had poor or absent knowledge (figure). Nearly one half $(7 / 15)$ of the high risk subjects had poor or absent knowledge of available therapy.

\section{KNOWLEDGE OF GENETICS}

In response to direct questions, 94 (49\%) subjects knew that the disease affects males and females equally, $76(40 \%)$ that it does not skip a generation, 96 $(50 \%)$ that the children of affected subjects are at $50 \%$ risk, and $138(73 \%)$ knew the risk to their offspring (table 1c). Forty-four (23\%) quoted a completely incorrect risk to their offspring, $29(15 \%)$ felt that it is restricted to one sex only, whereas $38(20 \%)$ described 
its mode of inheritance as recessive. Fifty-six (29\%) had a genetic knowledge score considered good or excellent, while $88(46 \%)$ had poor or absent knowledge (figure).

\section{PRESYMPTOMATIC (ULTRASOUND) TESTING}

We wanted to find out what effect the availability of presymptomatic testing had. A subsidiary aim was to discover how reliable subjects believed tests to be. Of the 190 in the cohort, 132 were originally at prior risk (the remainder being spouses), and, of these, 12 had alternative means of screening, leaving 120 . Of these, 17 were symptomatic at the time of diagnosis. Of the remaining 103 , eight have declined presymptomatic screening to date. Thus, of the $\mathbf{9 5}$ screened, 58 were affected, 30 were put at low risk, and seven remain at appreciable risk. Of the $\mathbf{5 8}$ diagnosed as affected on scanning, $99 \%$ said they felt confident in the result but only $79 \%$ viewed the scan as a ' $100 \%$ certain' diagnosis. Of the 30 put at low risk after negative scans, $\mathbf{9 0 \%}$ said they felt confident in the result while $67 \%$ viewed the negative scan as a 'guarantee' that they had not inherited the disease.

Of the subjects found to be affected after a positive presymptomatic test $(n=58), 11(19 \%)$ had modified their career plans, either by changing career or having employment refused. Twenty $(35 \%)$ had changed their sporting activities and $19(33 \%)$ had had insurance problems, either having a premium loaded or a policy refused. Forty-three (74\%) felt that they had suffered adverse social and psychological changes after their result.

Of the high risk group, eight declined ultrasound testing. Of these, four wanted to wait until they were older, one cited logistical problems with transport, and three did not want to know their status as they felt they could not cope with being positive for a disease with no cure.

The whole cohort was asked if it saw the need to develop a new presymptomatic test to improve upon ultrasound; $137(72 \%)$ did not. Of the $46(24 \%)$ who did wish for a new test, 16 wanted a test at an earlier age and 20 wanted a more accurate test.

\section{PRENATAL TESTING}

We were interested in attitudes to childbearing, and in assessing the likely demand for prenatal diagnosis. We asked the affected group $(n=85)$ whether the risk of the disease had influenced their childbearing. Fourteen (17\%) said it had, $48(56 \%)$ said it had not, and $23(27 \%)$ had not yet considered their reproductive plans. Of the 14 influenced by the risk of APKD, 11 had limited their family and three had been sterilised before having children. Of the 48 $(56 \%)$ who said there had been no influence, 25 felt that the disease was not serious enough to justify
Table 4 Q. Do you feel that the development of a prenatal test is a good thing?

\begin{tabular}{lccccc}
\hline $\begin{array}{l}\text { Status } \\
\text { group }\end{array}$ & Affected & $\begin{array}{c}\text { High } \\
\text { risk }\end{array}$ & $\begin{array}{c}\text { Low } \\
\text { risk }\end{array}$ & Spouses & Total \\
\hline Yes & $66(78 \%)$ & $9(60 \%)$ & $26(81 \%)$ & $41(71 \%)$ & $142(75 \%)$ \\
No & $16(18 \%)$ & $6(40 \%)$ & $5(16 \%)$ & $15(26 \%)$ & $42(22 \%)$ \\
Don't know & $3(4 \%)$ & & $1(3 \%)$ & $2(3 \%)$ & $2(3 \%)$ \\
Total & 85 & 15 & 32 & 58 & 190 \\
\hline
\end{tabular}

changing reproductive plans. Twenty-three of the 48 had in fact had their children before their diagnosis and, of these, six said that if they had known earlier they would have limited their families. Therefore, 20 (24\%) of the 85 affected subjects indicated that the risk of APKD had, or would have had, an influence on reproduction.

The whole cohort was asked whether it felt the development of a prenatal test was desirable; 142 (75\%) felt that it was, compared with $66(78 \%)$ of the affected group and nine $(60 \%)$ of the high risk group (table 4). A total of $78 \%$ of females and $70 \%$ of males wished to see a test developed.

Subjects were then asked whether they themselves would be interested in a prenatal test for APKD (table 5): $55(29 \%)$ of the whole cohort said they would compared with $21(25 \%)$ of those affected and two $(13 \%)$ of those at high risk. Interestingly, of the low risk group, for whom the question was hypothetical, $47 \%$ responded in the affirmative. Of the 55 who felt that they would be interested in a prenatal test, only 23 (19 females, four males) were in fact affected or at high risk and, of these, only nine were actually planning a family at the time of the study. Of these nine, eight were female and seven had no children to date.

Looking at the relationship between perception of the severity of APKD and interest in a prenatal test, $65 \%$ of those personally interested in a test, and at high risk of passing on the gene, considered the disease to be 'extremely serious' compared with $34 \%$ of the affected/high risk group not interested in a test. Although the perception of the disease differs in these two groups, the objective assessment of their experience in their own relatives did not differ between the two groups. Of the whole cohort, $50 \%$ felt the disease to be 'extremely serious'.

Subjects were asked an open ended question about

Table $5 Q$. Would you be interested in a prenatal test?

\begin{tabular}{lccccr}
\hline $\begin{array}{l}\text { Status } \\
\text { group }\end{array}$ & Affected & $\begin{array}{c}\text { High } \\
\text { risk }\end{array}$ & $\begin{array}{c}\text { Low } \\
\text { risk }\end{array}$ & Spouses & Total \\
\hline Yes & $21(25 \%)$ & $2(13 \%)$ & $15(47 \%)$ & $17(29 \%)$ & $55(29 \%)$ \\
No & $55(65 \%)$ & $13(87 \%)$ & $15(47 \%)$ & $37(64 \%)$ & $120(63 \%)$ \\
Don't know & $9(10 \%)$ & 15 & $2(6 \%)$ & $4(7 \%)$ & $15(15 \%)$ \\
Total & 85 & 15 & 32 & 58 & 190 \\
\hline
\end{tabular}


any aspects of prenatal testing they would find difficult to accept. Of the whole cohort $(n=190), 93$ (49\%) said that they disliked the idea of terminations being available for APKD, contrasting with $73 \%$ of the high risk group. Only $9 \%$ of the total cohort objected to termination of pregnancy in principle. Over a third of the cohort felt that the risk of the chorionic villus sampling procedure was worrying.

\section{Discussion}

The discovery of DNA markers linked to APKD has introduced new options with respect to presymptomatic testing and reproduction, as well as opening up future possibilities for gene therapy. Much of the decision making for individual subjects will depend upon their experience and perception of the disease and its consequences, as well as an understanding of the genetic risk.

The vast majority of the study cohort knew of the presence of renal cysts, and that these can lead to renal failure. The open ended question regarding other symptoms of the disease showed that they remembered those clinical features which either they had experienced personally or had seen in other relatives. This aspect is not so striking in terms of the therapy, where $46 \%$ of the cohort had experience of relatives either on dialysis or transplantation, but over $80 \%$ knew of the availability of both forms of treatment for patients with APKD. In qualitative terms only $16 \%$ of the cohort felt APKD was not a serious condition.

Patients with APKD are at increased risk of subarachnoid haemorrhages from rupture of intracranial aneurysms. It is usually accepted that to screen all affected subjects using cerebral arteriography is not necessary, owing to the associated risk of the technique, although newer, non-invasive measures may change this. ${ }^{15}$ Only nine subjects in our cohort knew of the risks of this potentially lethal complication, which underlies a reluctance to discuss this aspect with subjects from families in which SAHs have not occurred. Our nine subjects all came from two families in which more than one person has been affected by this complication.

Despite genetic counselling, and the long term follow up of a genetic register, knowledge of the genetic aspects was found to be variable, and indicated particular areas of misunderstanding. However, $73 \%$ of subjects correctly recalled the risk to their offspring, suggesting that while mechanisms of inheritance may not be recalled, the pertinent risk figure is. Furthermore, the knowledge of genetic aspects was better in APKD family members than it was in their spouses. Misinterpretation, or poor recall after genetic counselling, can result from many factors, including the emotional readiness at the time of counselling, the ability to remember the facts given, and the style and time taken by the counsellor. In particular, it may be that the use of diagrams to help with a full explanation of the mode of inheritance would decrease common misunderstandings; the linkage diagrams we have devised proved particularly useful when explaining the use of linked probes within families and the problems associated with recombination.

Of the 132 subjects from the cohort who were at prior risk of inheriting APKD, $81 \%$ had had some form of presymptomatic testing for the presence of $A P K D$, a figure at variance with the reported uptake of genetic presymptomatic testing for Huntington's chorea, ${ }^{32}$ even though both conditions are dominant and have an adult onset. This difference is probably the result in part of the well known availability of effective treatment for APKD. The availability of a non-invasive ultrasound scan for presymptomatic diagnosis will probably mean that DNA presymptomatic screening may not have the same immediate impact in APKD as it will for conditions where DNA provides the only possibility for presymptomatic tests, or where existing tests are more invasive, for example, polyposis coli. However, the impact of genetic screening for APKD will be more important for those who have negative scans in their early 20s and want to make reproductive decisions. In these cases, the results of ultrasound, and linkage can be combined. ${ }^{27}$ The use of linked probes for APKD will allow earlier testing, with greater accuracy (assuming the question of genetic heterogeneity is resolved). A total of $19 \%$ of this cohort felt that a test which was either more accurate, or could be done at an earlier age, would be preferable to the ultrasound test.

Of those subjects at prior risk of inheriting APKD, only eight declined ultrasound screening. However, among the APKD families generally, this figure is probably much higher, as $81 \%$ of the high risk subjects who were asked to participate declined. Clearly the choice not to have testing, and not to participate in the study, reflects their attitude towards the risk of the disease. It is important to remember that the very high uptake of presymptomatic testing in our cohort does partially represent a bias of subject participation very common in surveys of this sort. ${ }^{33}{ }^{34}$ However, even if all of the high risk group had participated, uptake would have been at least $64 \%$ in the group as a whole.

The diagnosis of an adult onset condition many years before the onset of symptoms could potentially have major adverse consequences. These include the possibility of discrimination in employment and financial matters (for example, life insurance) as well as the psychological impact of the result, and this has been discussed in relation to presymptomatic testing for other autosomal dominant conditions, such as Huntington's chorea. ${ }^{35}$ In this study $33 \%$ of those diagnosed presymptomatically had experienced 
problems with insurance, and $74 \%$ described feeling depressed or having changes in behaviour after diagnosis. As one subject said: "When I was positive, the cysts were visible on the screen, I came face to face with my own mortality". Although three-quarters felt they had experienced adverse psychosocial consequences after a presymptomatic test, we did not seek detailed information on the nature and extent of psychological sequelae to a positive diagnosis.

We were interested to know what effect, if any, APKD had had on reproductive behaviour. Although the cohort considered this a serious disease, and had a good recall of the risk to their offspring, only $17 \%$ of the affected group had in fact had no children or limited their families because of the risk. This group proportionally had a greater understanding of the clinical aspects, the therapy, and the genetics than the affected group as a whole, and when asked which factors had most influenced their decision regarding children, they cited a reluctance to watch their own offspring suffer with kidney problems ("I had a vision of all my children lined up on kidney machines"), a feeling that they wouldn't want a child to have to make the same adult decisions (both in terms of career and reproduction) as themselves, and the guilt which they would have to contend with if the condition were passed on.

A majority of the cohort felt that the development of a prenatal test was acceptable, although a minority of the cohort said they would personally be interested. Almost half of the cohort felt that APKD was not a valid reason for terminating a pregnancy, while only 9\% disagreed with termination generally. Comments such as "I'm not ill. If the child turns out to be as well and fit as me then it won't be bad" were very common. Clearly the adult onset, partially treatable nature of the condition makes termination of pregnancy a less acceptable choice than for seriously handicapping conditions apparent in newborns or children. A higher proportion of those at low genetic risk indicated that they would have had a prenatal test for APKD if they had been at high risk; it would seem that prenatal diagnosis may be more appealing in the abstract. Of those at risk of passing the APKD gene on to their offspring, and currently considering having children, nine $(23 \%)$ said they would be interested in a prenatal test and only one has actively pursued the matter.

About half of those family members invited to participate in the study agreed to be interviewed; therefore study bias must be considered. However, one would imagine that persons willing to participate in a study would be more openly facing the disease and its implications than those not willing to participate, and therefore it would be difficult to imagine that those not interviewed would be more likely to want prenatal diagnosis.

Comparing the groups who would accept/not accept prenatal diagnosis, no differences in knowledge scores were noted, but those who would accept prenatal diagnosis were more likely to perceive the disease as serious, even though the objective experiences of the disease were not different.

We conclude that even for persons with a realistic perception of the disease, and a good recall of the recurrence risk, the demand for prenatal diagnosis will be low.

We are grateful to our colleagues in the Regional Genetic Centre at St Mary's Hospital and in the Renal Unit at Manchester Royal Infirmary for their constructive comments. We also thank the APKD families who gave up their time to be interviewed; without their cooperation this study could not have taken place. This work was supported by the UK Department of Health and by the North Western Regional Health Authority.

1 Lejars F. Du gros rein polycystique de l'adulte. Paris, 1888.

2 Osthanondh V, Potter EL. Pathogenesis of polycystic kidneys. Arch Pathol 1964;77:466-509.

3 Steiner DR. Uber grosscystiche Degeneration der Nieren und der Leber. Disch Med Wochenschr 1899;25:677-8.

4 Cairns HWB. Heredity in polycystic disease of the kidneys. $Q \mathcal{F}$ Med 1925;18:359-70.

5 Dalgaard OZ. Bilateral polycystic disease of the kidneys: a follow up of 284 patients and their families. Acta Med Scand (Suppl) 1957;158:1-251.

6 Shokier MHK. Expression of "adult" polycystic renal disease in the fetus and newborn. Clin Genet 1978;14:61-72.

7 Taitz LS, Brown CB, Blank CE, Steiner GM. Screening for polycystic kidney disease: importance of clinical presentation in the newborn. Arch Dis Child 1987;62:45-9.

8 Milutinovic J, Fialkow PJ, Agoda LY, Phillips LA, Rudd TG, Bryant JI. Autosomal dominant polycystic kidney disease; symptoms and clinical findings. $Q \mathcal{F}$ Med 1984;212:511-22.

9 Delaney VB, Adler S, Burns F, Lucinia M, Segel P, Fraley D. Autosomal dominant polycystic kidney disease: presentation, complications and prognosis. Am $\mathcal{F}$ Kidney Dis 1985;2:104-11.

10 Kramer P, Broyer M, Brunner FP, et al. Combined report on regular dialysis and transplantation in Europe. XII, 1981. Proc EDTA 1982;19:2-59.

11 Churchill DN, Bear JC, Morgan J, Payne RN, McMananon PJ, Gault MH. Prognosis of adult onset polycystic kidney disease re-evaluated. Kidney Int 1984;2:190-3.

12 Hartnett $M$, Bennett $W$. Extrarenal manifestations of cystic kidney disease. In: Gardner KD Jr, ed. Cystic diseases of the kidney. New York: Wiley, 1976:201-19.

13 Grunfeld JP, Albouze G, Jungers P, et al. Liver changes and complications in adult polycystic kidney disease. Adv Nephrol 1985;14:1-20.

14 Leier CV, Baker PB, Kilman JW, Wooley CF. Cardiovascular abnormalities associated with adult polycystic kidney disease. Ann Intern Med 1984;5:683-8.

15 Levey AS, Pauker SG, Kassirer JP. Occult intracranial aneurysms in polycystic kidney disease. When is cerebral arteriography indicated? N Engl fु Med 1983;308:986-94.

16 Saifuddin A, Dathan JRE. Adult polycystic kidney disease and intracranial aneurysms. Br Med $\mathcal{f} 1987 ; 295: 526$.

17 Wolf B, Rosenfield AT, Taylor KJW, Rosenfield V, Gottlieb S, Hsia YE. Pre-symptomatic diagnosis of adult onset polycystic kidney disease by ultrasonography. Clin Genet 1978;14:1-7.

18 Hogewind BL, Veltkamp J, Koch C, de Graeff J. Genetic counselling for adult polycystic kidney disease. Ultrasound a useful tool in presymptomatic diagnosis? Clin Genet 1980;18: 168-72.

19 Milutinovic JM, Fialkow PJ, Phillips LA, et al. Autosomal dominant polycystic kidney disease: early diagnosis and data for genetic counselling. Lancet 1980;i:1203-6. 
20 Bear JC, McManamon P, Morgan J, et al. Age at clinical onset and at ultrasonographic detection of adult polycystic kidney disease-data for genetic counselling. Am F Med Genet 1984;18: 45-54.

21 Zerres K, Weiss H, Bulla M, Roth B. Prenatal diagnosis of an early manifestation of autosomal dominant adult type polycystic kidney disease. Lancet 1982; ii: 988.

22 Main D, Mennuti MT, Cornfeld D, Coleman B. Prenatal diagnosis of adult polycystic kidney disease. Lancet 1983;ii: 337-8.

23 Reeders ST, Breuning MH, Davies KE, et al. A highly polymorphic DNA marker linked to adult polycystic kidney disease on chromosome 16. Nature 1985;317:542-4.

24 Breuning MH, Reeders ST, Brunner H, et al. Improved early diagnosis of adult polycystic kidney disease with flanking DNA markers. Lancet 1987;ii:1359-61.

25 Romeo G, Devoto M, Costa G, et al. A second genetic locus for autosomal dominant polycystic kidney disease. Lancet 1988;ii: 8-11.

26 Kimberling WJ, Fain PR, Kenyon JB, Goldgar D, Sujansky E, Gabow MD. Linkage heterogeneity of autosomal dominant polycystic kidney disease. $N$ Engl f Med 1988;319:913-7.

27 Elles RG, Read AP, Hodgkinson KA, Watters A, Harris R.
Recombination or heterogeneity: is there a second locus for adult polycystic kidney disease? $f$ Med Genet 1990;27:413-7.

28 Hultén M. Linkage heterogeneity in autosomal dominant poly cystic kidney disease. Lancet 1988;ii:451-2.

29 Reeders ST, Zerres K, Gal A, et al. First prenatal diagnosis of autosomal dominant polycystic kidney disease using a DNA probe. Lancet 1986;ii:6-7.

30 Macinol AM, Watson ML, Wright AF. Implications of a genetic screening programme for polycystic renal disease. Aspects of Renal Care 1986;1:219-22.

31 Sahney S, Weiss L, Levin L. Genetic counselling in adult polycystic kidney disease. Am $\mathcal{f}$ Med Genet 1982;11:461-8.

32 Craufurd D, Dodge A, Kerzin-Storrar L, Harris R. Uptake of pre-symptomatic predictive testing for Huntington's disease. Lancet 1989;ii:603-5.

33 Stern RS, Eldridge R. Attitudes of patients and their relatives to Huntington's disease. $\mathcal{f}$ Med Genet 1975;12:217-23.

34 Kessler S, Field T, Worth L, Mosbarger H. Attitudes of persons at risk for Huntington's disease toward predictive testing. $A m \mathcal{F}$ Med Genet 1987;26:259-70.

35 Craufurd D, Harris R. Ethics of predictive testing for Huntington's chorea: the need for more information. Br Med $\mathcal{F}$ 1986;293: 249-51. 